\title{
Heparin attenuates TNF- $\alpha$ induced inflammatory response through a CD11b dependent mechanism
}

\author{
A Salas, M Sans, A Soriano, J C Reverter, D C Anderson, J M Piqué, J Panés
}

\begin{abstract}
Background-In addition to its anticoagulant properties, heparin has antiinflammatory effects, the molecular and mechanistic bases of which are incompletely defined.

Aims-The current studies were designed to test the hypothesis that heparin abrogates the expression or function of leucocyte-endothelial adherence molecules which are fundamental to the acute inflammatory response.
\end{abstract}

Methods-The effects of heparin on tumour necrosis factor alpha (TNF- $\alpha$ ) induced leucocyte rolling, adhesion, and migration as well as vascular permeability were assessed in rat mesenteric venules using intravital microscopy. Expression of adhesion molecules was quantitated using a double radiolabelled monoclonal antibody ( $\mathrm{mAb}$ ) binding technique in vivo $(\mathbf{P}$-selectin, intercellular cell adhesion molecule type 1 (ICAM-1), and vascular cell adhesion molecule 1 (VCAM-1)) or flow cytometry (CD11a, CD11b, and L-selectin). Ex vivo binding of heparin to neutrophils was assessed by flow cytometry.

Results-TNF- $\alpha$ induced a significant increase in leucocyte rolling, adhesion, and migration, and vascular permeability, coincident with a significant increase in expression of P-selectin, ICAM-1, and VCAM-1. Ex vivo assessment of blood neutrophils showed significant upregulation of CD11a and CD11b and significant downregulation of $\mathrm{L}$-selectin within five hours of TNF- $\alpha$ administration. Heparin pretreatment significantly attenuated leucocyte rolling, adhesion, and migration but did not affect expression of cell adhesion molecules or vascular permeability elicited by TNF- $\alpha$ administration. Binding of heparin was significantly increased on blood neutrophils obtained five hours after TNF- $\alpha$ administration. Preincubation with an anti-CD11b mAb but not with an anti-CD11a or anti-L-selectin antibody significantly diminished heparin binding ex vivo.

Conclusions-Our results support the concept that the anti-inflammatory effects of heparin involve attenuation of a CD11b dependent adherent mechanism. (Gut 2000;47:88-96)

Keywords: CD11; P-selectin; L-selectin; ICAM-1; VCAM-1; inflammatory bowel disease
Several uncontrolled studies have suggested that heparin may be potentially therapeutic in the clinical management of both ulcerative colitis and Crohn's disease. Although these studies included only a limited number of patients, they demonstrated apparent beneficial effects of heparin with no associated haemorrhagic complications. ${ }^{1-8}$ In addition, heparin has been shown to prevent macroscopic inflammatory lesions in an animal model of experimental colitis. ${ }^{9}$ However, the molecular mechanisms by which heparin may help patients with inflammatory bowel disease (IBD) are unknown.

Tumour necrosis factor alpha $(\mathrm{TNF}-\alpha)$ plays a pivotal role in the pathophysiology of IBD as levels of this chemokine are elevated in biopsies and peripheral blood cells obtained from patients with ulcerative colitis and Crohn's disease, ${ }^{10}{ }^{11}$ and systemically administered antibodies against TNF- $\alpha$ have demonstrated efficacy in the treatment of some patients with Crohn's disease. ${ }^{12}$

A large body of evidence supports the concept that heparin has anti-inflammatory actions; among these include modulation of some of the pathophysiological effects of endotoxin and TNF- $\alpha$, such as neutrophil migration, oedema formation, pulmonary hypertension, and hypoxaemia. ${ }^{13-18}$ Moreover, heparin has been shown to suppress selected neutrophil functions such as superoxide generation $^{19}$ and chemotaxis in vitro, ${ }^{20}{ }^{21}$ to reduce eosinophil migration, ${ }^{22}$ and to diminish vascular permeability. ${ }^{23}$

Among the mechanisms that may account for the anti-inflammatory actions of heparin, binding of this glycosaminoglycan to adhesion molecules expressed on the surface of activated endothelial cells and/or leucocytes has been proposed. Recent studies in vitro have demonstrated the ability of heparin to effectively bind to endothelial P-selectin but not E-selectin, ${ }^{13} 24$ as well as L-selectin and CD11b/CD18 expressed on neutrophils. ${ }^{25}{ }^{26}$ Taken together, these reports suggest that the therapeutic actions of heparin observed in IBD patients may involve attenuation of inflammatory processes as well as a hypercoaguable state

Abbreviations used in this paper: aPTT, partial thromboplastin time; BBS, bicarbonate buffered saline; BSA, bovine serum albumin; FITC, fluorescein isothiocyanate; fMLP, $N$-formyl methionyl leucyl phenylalanine; IBD, inflammatory bowel disease; ICAM-1, intercellular cell adhesion molecule type 1; Ig, immunoglobulin; IL-8, interleukin 8; mAb, monoclonal antibody; PBS, phosphate buffered saline; TNF- $\alpha$, tumour necrosis factor alpha; VCAM-1, vascular cell adhesion molecule 1; PE, phycoerythrin.

08036, Spain. Email:

Accepted for publication 11 January 2000 
associated with clinical exacerbation of IBD, effects which may promote mucosal repair.

In the present study, a rodent model of $\mathrm{TNF}-\alpha$ induced mesenteric inflammation was used to evaluate the possibility that heparin attenuates leucocyte-endothelial adherence interactions as a basis for its anti-inflammatory effects. Specific protocols in this model were carried out to evaluate the capacity of heparin: (1) to regulate the expression of vascular cell adhesion molecules (P-selectin, intercellular cell adhesion molecule type 1 (ICAM-1), or vascular cell adhesion molecule 1 (VCAM-1)) in vivo, (2) to attenuate leucocyte rolling, adhesion, and migration, and associated vascular permeability, and (3) to regulate the expression or inhibit functions of leucocyte adhesion molecules (CD11a, CD11b, or L-selectin).

\section{Materials and methods}

INTRAVITAL MICROSCOPY Experimental protocol

Male Sprague-Dawley rats weighing 250-300 g were studied (Charles River, Saint Aubin les-Elbeuf, France). Animals were allowed free access to food and water until the time of the study. The following groups of animals were studied: basal untreated rats, rats injected with mouse recombinant TNF- $\alpha 5 \mathrm{mg} / \mathrm{kg}$ intraperitoneally (Genzyme, Cambridge, Massachusetts, USA), and rats pretreated with a subcutaneous dose of unfractionated calcium heparin 50, 500, or $1500 \mathrm{U} / \mathrm{kg}$ (Wasserman, Barcelona, Spain) 90 minutes before receiving TNF- $\alpha$. These experiments were performed five hours after TNF- $\alpha$ injection. To assess the effects of heparin on blood coagulation, partial thromboplastin time (aPTT) was measured (Actin FS; Dade Behring, Marburg, Germany) in the different groups of rats who received one of three doses of heparin or vehicle. To characterise the anti-inflammatory action of heparin over time, additional groups of animals pretreated with $500 \mathrm{U} / \mathrm{kg}$ of calcium heparin (the dose with the maximal anti-inflammatory effect) or vehicle were challenged with TNF- $\alpha$ and studied two hours later.

To assess the ability of heparin to block the inflammatory response to a chemotactic factor, groups of animals $(n=5)$ were treated with a subcutaneous dose of either vehicle or calcium heparin $(500 \mathrm{U} / \mathrm{kg})$ six hours before superfusion of the mesentery with $N$-formyl methionyl leucyl phenylalanine (fMLP) $0.1 \mu \mathrm{M}$ (Sigma, Madrid) for 30 minutes. The Guide for the Care and Use of Laboratory Animals (NIH Publication No. 86-23, revised 1985) and the guidelines for procedures for animal experiments from the Generalitat de Catalunya were followed.

\section{Surgical techniques}

Anaesthesia was induced by intraperitoneal injection of thiobutabarbital $(100 \mathrm{mg} / \mathrm{kg}$ body weight; Inactin, Research Biochemicals International, Natick, Massachusetts, USA). A tracheotomy was performed to facilitate breathing, and the right carotid artery was cannulated to monitor blood pressure throughout the experiment. A midline abdominal incision was made.

\section{Intravital microscopy}

A section of the mesentery from the small bowel was exteriorised through the midline abdominal incision previously performed. Rats were placed over a steel microscope board in a position that allowed the section of the mesentery to be observed through a glass slide covering a $3.5 \times 3.5 \mathrm{~cm}$ hole centred on the board. The exposed intestine was covered with bicarbonate buffered saline (BBS, $\mathrm{pH} 7.4$ ) soaked gauze, and the mesentery was continuously superfused with $\mathrm{BBS}$ at $37^{\circ} \mathrm{C}, 2.5 \mathrm{ml} / \mathrm{min}$, to avoid dehydration. The steel board was placed on the stage of an inverted microscope (Diaphot 300, Nikon, Tokyo, Japan) equipped with a CF Fluor $40 \times$ objective lens (Nikon, Tokyo, Japan). The preparation was transilluminated with a $12 \mathrm{~V}, 100 \mathrm{~W}, \mathrm{DC}$ stabilised light source. A 3CCD camera (model DXC-930P, Sony, Tokyo, Japan) mounted on the microscope projected the image onto a colour monitor (Trinitron KX-14CP1, Sony, Tokyo, Japan), and the images were captured on video tape (SR-S368E videocassette recorder, JVC, Tokyo Japan). Rectal temperature was maintained between 36.5 and $37.5^{\circ} \mathrm{C}$ using an infrared heat lamp. Single unbranched venules with a diameter of 25-35 $\mu \mathrm{m}$ and length $>100 \mu \mathrm{m}$ were studied. Venular diameter $\left(D_{v}\right)$ was measured on line using a video caliper (Microcirculation Research Institute, Texas A\&M University, College Station, Texas, USA). The number of rolling, adherent, and migrated leucocytes was measured off line during playback of video taped images. A leucocyte was considered adherent to the venular wall if it remained stationary for 30 seconds or longer. Adherent leucocytes were quantified as the number per $100 \mu \mathrm{m}$ length of venule. Leucocyte migration was expressed as the number of leucocytes per microscopic field $\left(1.7 \times 10^{-2}\right.$ $\mathrm{mm}^{2}$ ). Rolling leucocytes were defined as those white blood cells circulating at a slower velocity than erythrocytes in the same vessel. Leucocyte rolling velocity was determined from the time required for a leucocyte to traverse a $50 \mu \mathrm{m}$ distance along the length of the venule and is expressed as $\mu \mathrm{m}$ per second. The flux of rolling leucocytes was measured as the number of white blood cells that could be seen rolling within a small $(10 \mu \mathrm{m})$ viewing area of the vessel, using the same area throughout the experiment. The number of rolling leucocytes per $100 \mu \mathrm{m}$ venule length was calculated by dividing leucocyte flux by leucocyte rolling velocity.

Centreline red blood cell velocity was measured with an optical Doppler velocimeter (Microcirculation Research Institute, Texas A\&M University, College Station, Texas, USA) connected to a CCD colour camera (Sony, Tokyo, Japan) through a multi-image module. Venular blood flow was calculated from the product of mean red blood cell velocity $\left(\mathrm{V}_{\text {mean }}=\right.$ centreline red blood cell velocity/1.6) and microvascular cross sectional area, assuming the cylindrical geometry of the vessel. 
Venular wall shear rate $(\gamma)$ was calculated from the Newtonian definition: $\gamma=8 \times\left(\mathrm{V}_{\text {mean }} / \mathrm{D}_{\mathrm{v}}\right)$.

MEASUREMENT OF ENDOTHELIAL ADHESION MOLECULE EXPRESSION

Experimental protocols

P-selectin, ICAM-1, and VCAM-1 expression was measured in the following groups of rats ( $\mathrm{n}=5$ per group): untreated rats, $\mathrm{TNF}-\alpha$ stimulated rats $(5 \mu \mathrm{g} / \mathrm{kg}$ body weight intraperitoneally), and rats who received a subcutaneous dose of heparin (500 U/kg body weight) 90 minutes before TNF- $\alpha$ injection. P-selectin expression was determined two hours after $\mathrm{TNF}-\alpha$ stimulation, as an increase in leucocyte rolling was detected at this time following TNF- $\alpha$ administration. Expression of ICAM-1 and VCAM-1 was assessed at five hours after TNF- $\alpha$, as this time was associated with maximal leucocyte adhesion and migration in a previous study. ${ }^{27}$

\section{Animal procedures}

At the time of the study, anaesthesia was induced as described above. The right carotid artery and right jugular vein were cannulated.

\section{Monoclonal antibodies}

The monoclonal antibodies (mAbs) used for the in vivo assessment of P-selectin, ICAM-1, and VCAM-1 expression were: RMP-1, a murine immunoglobulin $\mathrm{G}_{2 \mathrm{a}}\left(\operatorname{IgG}_{2 \mathrm{a}}\right)$ against rat and mouse P-selectin ${ }^{28} ; 1 \mathrm{~A} 29$, a murine $\mathrm{IgG}_{1}$ against rat $\mathrm{ICAM}-1^{29} ; 5 \mathrm{~F} 10$, a murine $\mathrm{IgG}_{2 \mathrm{a}}$ against rat VCAM- $1^{30}$; and P-23, a nonbinding murine $\mathrm{IgG}_{1}$ directed against human, but not rat, P-selectin. ${ }^{31}$ MAbs 1A29, RMP-1, and P-23 were scaled up and purified by protein A/G chromatography at Pharmacia and Upjohn Laboratories (Kalamazoo, Minnesota, USA). 5F10 was kindly provided by Dr Roy Lobb, Biogen Inc. (Cambridge, Massachusetts, USA).

\section{Radioiodination of monoclonal antibodies}

Binding mAbs directed against P-selectin (RMP-1), ICAM-1 (1A29), or VCAM-1 (5F10) were labelled with ${ }^{125} \mathrm{I}$ while the non-binding $\mathrm{mAb}(\mathrm{P}-23)$ was labelled with ${ }^{131} \mathrm{I}$. Radioiodination of the mAbs was performed by the iodogen method. ${ }^{32}$ Labelled mAbs were stored at $4^{\circ} \mathrm{C}$ and used within three weeks after the labelling procedure. The specific activity of labelled $\mathrm{mAbs}$ was $\cong 0.5 \mathrm{mCi} / \mathrm{mg}$.

To measure endothelial P-selectin expression, a mixture of $5 \mu \mathrm{g}$ of ${ }^{125} \mathrm{I}$ anti-P-selectin $\mathrm{mAb}$ (RMP-1), $5 \mu \mathrm{g}$ of ${ }^{131} \mathrm{I}$ non-binding $\mathrm{mAb}$ (P-23), and $10 \mu \mathrm{g}$ of unlabelled anti-P-selectin $\mathrm{mAb}$ was administered. In experiments designed to assess ICAM-1 expression, a mixture of $5 \mu \mathrm{g}$ of ${ }^{125} \mathrm{I}$ anti-ICAM-1 mAb (1A29), $5 \mu \mathrm{g}$ of ${ }^{131} \mathrm{I}$ non-binding mAb (P-23), and $245 \mu \mathrm{g}$ of unlabelled anti-ICAM-1 mAb was administered through the jugular vein catheter. VCAM-1 was assessed by administration of 20 $\mu \mathrm{g}$ of ${ }^{125} \mathrm{I}$ anti-VCAM-1 mAb (5F10) and $5 \mu \mathrm{g}$ of ${ }^{131} \mathrm{I}$ non-binding $\mathrm{mAb}(\mathrm{P}-23)$. Doses of antiP-selectin, anti-ICAM-1, and anti-VCAM-1 proved to be saturating in vivo in this experimental model. ${ }^{33-35}$
Blood samples were obtained through the carotid artery catheter five minutes after injection of the mAb mixture. Thereafter, animals were heparinised ( $1 \mathrm{mg} / \mathrm{kg}$ sodium heparin intravenously) and rapidly exsanguinated. Entire organs were then harvested and weighed.

\section{Calculations}

${ }^{125} \mathrm{I}$ (binding $\mathrm{mAb}$ ) and ${ }^{131} \mathrm{I}$ (non-binding $\mathrm{mAb}$ ) activities in each organ and in $100 \mu \mathrm{l}$ aliquots of cell free plasma were counted in a Cobra II gamma counter (Packard, Meridien, Australia) with automatic correction for background activity and spillover. The injected activity in each experiment was calculated by counting a 5 $\mu \mathrm{l}$ sample of the mixture containing the radiolabelled mAbs. The accumulated activity of each $\mathrm{mAb}$ in an organ was expressed as nanograms of binding antibody per gram of tissue (ng $\mathrm{mAb} / \mathrm{g}$ tissue). The formula used to calculate P-selectin, ICAM-1, or VCAM-1 expression was as follows: endothelial expression $=\left[\left(\mathrm{cpm}^{125} \mathrm{I}\right.\right.$ organ $\times \mathrm{g}^{-1} \times \mathrm{cpm}{ }^{125} \mathrm{I}$ injected $\left.{ }^{-1}\right)-\left(\mathrm{cpm}^{131} \mathrm{I}\right.$ organ $\times \mathrm{g}^{-1} \times \mathrm{cpm}^{131} \mathrm{I}$ injected $\left.^{-1}\right) \times\left(\mathrm{cpm}^{125} \mathrm{I}\right.$ in plasma $) /\left(\mathrm{cpm}^{131} \mathrm{I}\right.$ in plasma)] $\times$ ng injected binding $\mathrm{mAb}$.

\section{FLOW CYTOMETRY}

\section{Neutrophil adhesion molecule expression}

Citrated blood samples $(3.15 \mathrm{ml})$ were obtained by heart puncture, either before (basal conditions) or at two and five hours after TNF- $\alpha$ injection, in placebo and heparin treated animals. Blood samples were diluted in an equal volume of $6 \%$ dextran in saline (Sigma, Madrid, Spain), pH 7.6, and allowed to precipitate for 30 minutes at room temperature. Erythrocyte free phase was carefully transferred to a plastic tube and centrifuged for five minutes at $500 \mathrm{~g}$. Leucocytes were resuspended in $500 \mathrm{ml}$ RPMi medium containing $2 \%$ fetal calf serum and $1 \%$ rabbit serum (Life Technologies, New York, USA). Aliquots of $50 \mu \mathrm{l}$ were incubated for 30 minutes with either an antibody against CD11a (WT.1; Labgen, Barcelona, Spain), CD11b (MRC OX-42; Labgen), or L-selectin (LAM 1.116) at a concentration of $10 \mu \mathrm{g} / \mathrm{ml}$. Anti-L-selectin antibody was a kind gift from Dr Pilar Pizcueta (Hepatology Department, Hospital Clínic, Barcelona, Spain); this antibody has been shown to effectively block leucocyte rolling in vivo. ${ }^{36}$ Additional samples from each animal were preincubated with heparin-bovine serum albumin (BSA) (Sigma Química, Madrid, Spain) to assess the ability of this molecule to block the binding of anti-CD11a, anti-CD $11 \mathrm{~b}$, or anti-L-selectin mAbs. Negative control samples were incubated with phosphate buffered saline (PBS) containing FCS and sodium azide. A goat antimouse IgG-fluorescein isothiocyanate (FITC) conjugate (Caltag, San Francisco, California, USA) was used as a secondary antibody. After labelling with this antibody, leucocyte suspensions were washed and erythrocytes were lysed using FACS brand lysing solution (Becton Dickinson, San José, California, USA). Washed cells were resuspended 
A
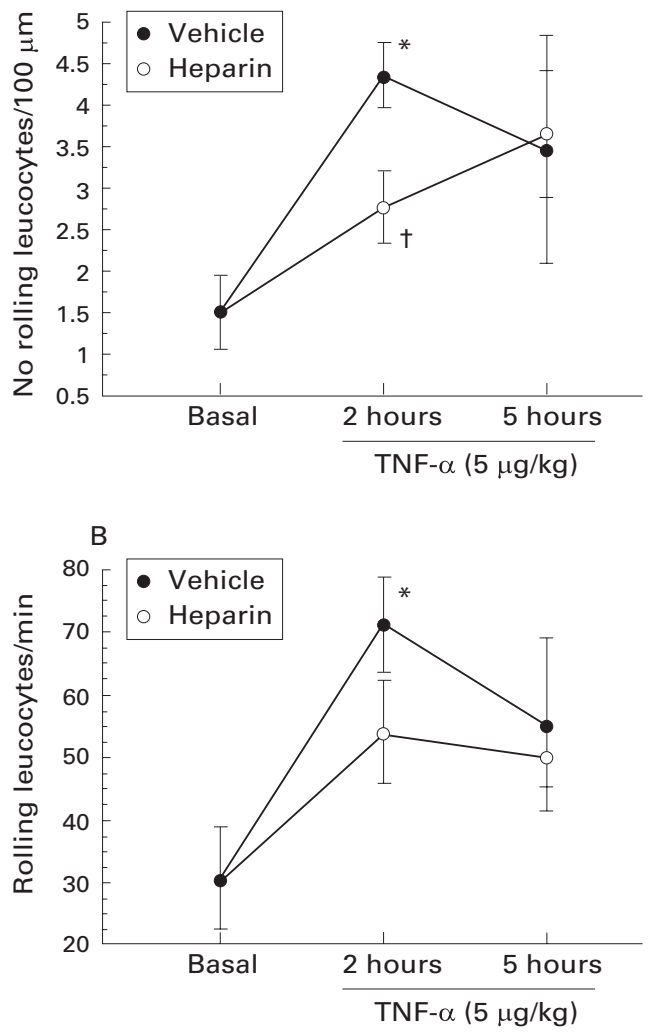

Figure 1 Number of rolling leucocytes (cells/100 $\mu \mathrm{m}$ ) and flux of rolling leucocytes (cells/minute) under baseline conditions (Basal) and two and five hours following $T N F-a$ injection in heparin and vehicle pretreated animals $\left(n=5\right.$ per group). ${ }^{*} p<0.05$ v basal; $t p<0.05$ v vehicle treated rats.

in $300 \mu \mathrm{l}$ of PBS with formalin and kept at $4^{\circ} \mathrm{C}$ until analysed.

FACSscan flow cytometer (Becton Dickinson, San José, California, USA) and CELLQUEST software were used for acquisition and analysis of the data. Populations of neutrophilic leucocytes were identified from forward and side scatter characteristics on dot plot profiles and were analysed for fluorescence intensity using fixed defined gates. At least 5000 neutrophils per sample were acquired.

\section{Heparin binding to neutrophils}

Additional experiments were performed to assess the ability of heparin to bind to leucocytes and to determine if this binding occurs through a CD11a, CD11b, or L-selectin-dependent mechanism. Leucocytes were obtained from rats under baseline conditions or five hours after stimulation with TNF- $\alpha$, as described above, and incubated with heparin-BSA as a negative control or heparin-BSA-biotin (Sigma Química, Madrid, Spain) at $1 \mathrm{mg} / \mathrm{ml}$ for 30 minutes. Aliquots of these samples were preincubated with either PBS, anti-CD11a, anti-CD11b, or anti-Lselectin mAbs. Thereafter, leucocytes were washed once with PBS and incubated with streptavidin-phycoerythrin (PE) $\quad 1 \mu \mathrm{g} / \mathrm{ml}$ (Southern Biotechnology Associates, Birmingham, Alabama, USA) for 30 minutes at $4^{\circ} \mathrm{C}$. Erythrocyte lysis was performed using FACS brand lysing solution (Becton Dickinson).
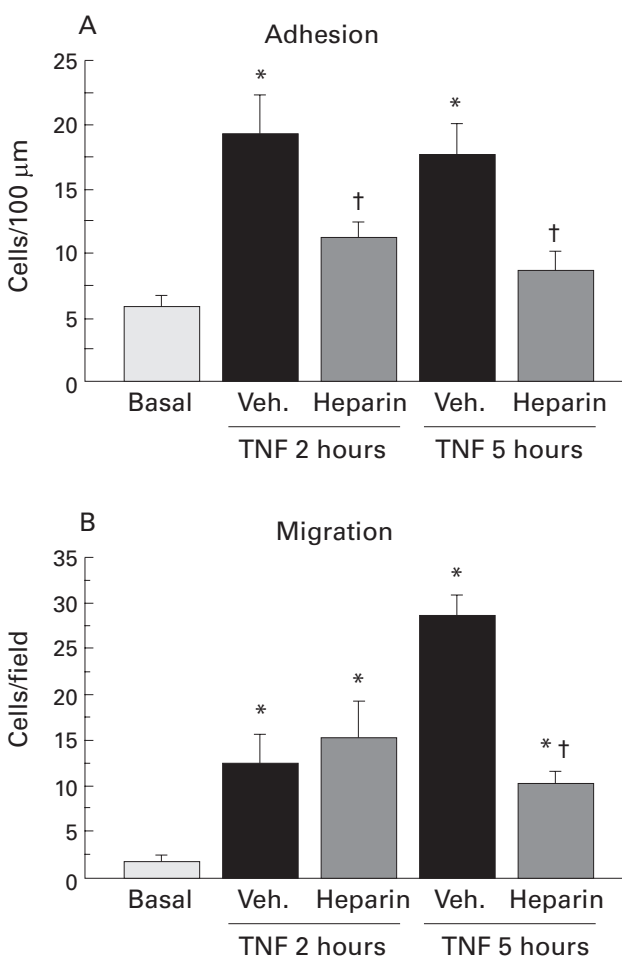

Figure 2 Number of adherent leucocytes (in $100 \mu \mathrm{m}$ length of venules) or migrated cells (per field) under basal conditions, and two and five hours following TNF-a administration in rats pretreated with saline (vehicle) or heparin ( $n=5$ per group). ${ }^{\star} p<0.05 v$ basal; $t p<0.05 v$ vehicle treated rats.

Washed leucocyte suspensions were resuspended in $300 \mu \mathrm{l}$ of PBS with formalin and kept at $4^{\circ} \mathrm{C}$ before being analysed as described above.

STATISTICAL ANALYSIS

All data were analysed using analysis of variance with Bonferroni as a post hoc test and a Student's paired or unpaired $t$ test where appropriate. All values are reported as mean (SEM). Statistical significance was set at $\mathrm{p}<0.05$.

\section{Results}

INFLAMMATORY RESPONSE TO TNF- $\alpha$ IN MESENTERIC VENULES: EFFECTS OF HEPARIN PRETREATMENT

A single intraperitoneal dose of $5 \mathrm{mg} / \mathrm{kg}$ of mouse recombinant TNF- $\alpha$ induced an acute inflammatory response in rat mesenteric postcapillary venules. Two hours after TNF- $\alpha$ injection there was a significant increase in the flux and number of rolling leucocytes compared with baseline values (fig 1). At this time point, the numbers of adherent and migrated leucocytes were significantly elevated compared with baseline levels (fig 2). When leucocyte-endothelial cell interactions were studied five hours after challenging with TNF- $\alpha$, a decrease in flux and number of rolling leucocytes, and a significant increase in the number of migrated leucocytes were observed compared with values observed two hours after TNF- $\alpha$ stimulation, but no change in the level of leucocyte adhesion was observed at this later time (figs 1,2). 
Table 1 Effect of different doses of calcium heparin on TNF-a induced leucocyte adhesion and migration ( $n=4-5$ per group)

\begin{tabular}{|c|c|c|c|c|c|}
\hline & \multirow[b]{2}{*}{ Basal } & \multirow[b]{2}{*}{$T N F-\alpha$} & \multicolumn{3}{|c|}{$T N F-a+h e p a r i n$} \\
\hline & & & $50 \mathrm{U} / \mathrm{kg}$ & $500 \mathrm{U} / \mathrm{kg}$ & $1500 \mathrm{U} / \mathrm{kg}$ \\
\hline Adhesion $($ cells $/ 100 \mu \mathrm{m})$ & $6.0(0.9)$ & $17.9(2.3)^{\star}$ & $16.8(5.1)$ & $8.8(1.4)+\dagger$ & $10.9(2.2)$ \\
\hline Emigration (cells/field) & $2.0(0.4)$ & $28.7(2.0)^{\star}$ & $24.0(5.4)^{\star}$ & $10.2(1.1)^{\star}+\dagger$ & $19.0(5.3)^{\star}$ \\
\hline
\end{tabular}

Pretreatment of rats with $50 \mathrm{U} / \mathrm{kg}$ of heparin had no effect on TNF- $\alpha$-induced leucocyte adhesion and migration whereas $500 \mathrm{U} / \mathrm{kg}$ significantly reduced the number of adherent and migrated cells five hours after TNF- $\alpha$ administration. Higher doses of heparin up to 1500 $\mathrm{U} / \mathrm{kg}$ did not further reduce leucocyte adhesion in response to $\mathrm{TNF}-\alpha$ and these doses were less effective in blocking leucocyte migration (table 1). Therefore, a dose of $500 \mathrm{U} / \mathrm{kg}$ was selected for use in all subsequent experiments.

Heparin $500 \mathrm{U} / \mathrm{kg}$ blocked the increase in leucocyte rolling observed two hours after treatment with $\mathrm{TNF}-\alpha$ (fig 1) and significantly reduced adhesion when observed at this time (fig 2). Heparin treatment did not modify the level of leucocyte migration observed two hours after administration of TNF- $\alpha$.

INCREASE IN PERMEABILITY IN RESPONSE TO TNF- $\alpha$ : EFFECT OF HEPARIN ADMINISTRATION $\mathrm{TNF}-\alpha$ induced inflammation of mesenteric postcapillary venules was associated with an increase in vascular permeability. Vascular permeability to FITC labelled albumin assessed in the current study was significantly increased at both two and five hours following TNF- $\alpha$ injection $(0.79(0.11)$ and $0.78(0.14) v 0.16$ $(0.1) ; \mathrm{p}<0.05)$. Pretreatment with heparin at any of the doses $(50,500$, or $1500 \mathrm{U} / \mathrm{kg}$ ) did not significantly reduce the increased vascular permeability induced by TNF- $\alpha(0.89$ (0.5), $0.43(0.18)$, and $0.76(0.27)$ respectively; NS, heparin treatment $v$ no treatment).

ENDOTHELIAL ADHESION MOLECULE EXPRESSION IN RESPONSE TO TNF- $\alpha$ : EFFECT OF HEPARIN PRETREATMENT

Endothelial ICAM-1 and VCAM-1 expression Expression of ICAM-1 and VCAM-1 was significantly increased in all organs, including the stomach, small and large bowel, pancreas, heart, kidneys, and muscle (tables 2,3 ) as well as in the mesenteric vascular endothelium (fig
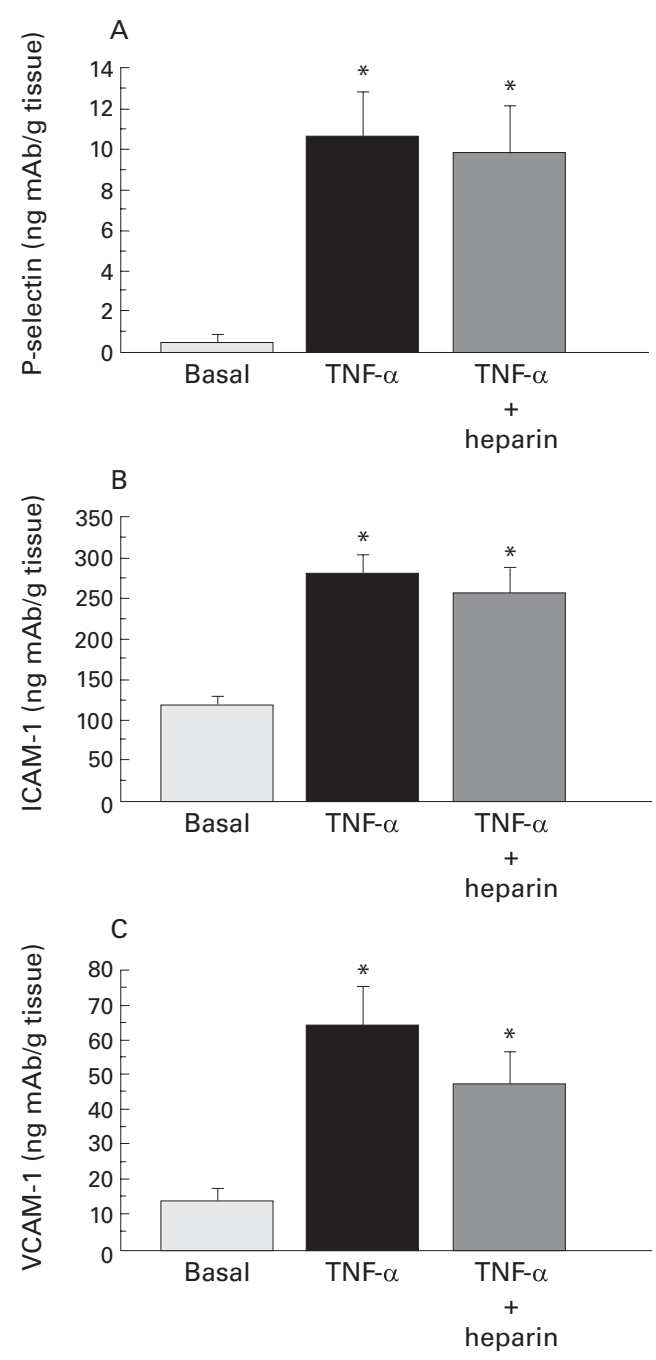

Figure 3 P-selectin, intercellular cell adhesion molecule type 1 (ICAM-1), and vascular cell adhesion molecule 1 (VCAM-1) endothelial expression in mesentery, expressed as $n g$ of binding antibody accumulated per gram of tissue ( $n=4-5$ per group), under basal conditions, following TNF- $a$ administration, and in rats pretreated with heparin. ${ }^{*} p<0.05$ v basal.

3) when assessed five hours following TNF- $\alpha$ administration compared with baseline conditions. As shown in fig 3 pretreatment of a cohort of rats with heparin $(500 \mathrm{U} / \mathrm{kg})$ did not significantly diminish TNF- $\alpha$ induced expression of either of these cell adhesion molecules

Table 2 Endothelial expression of ICAM-1 (ng of $m A$ b/g tissue) on different organs under basal unstimulated conditions ( $n=4)$ or five hours after $T N F-a$ injection, in vehicle or heparin pretreated rats $(n=4)$

\begin{tabular}{|c|c|c|c|c|c|c|c|c|c|}
\hline & Lung & Heart & Pancreas & Stomach & Small bowel & Caecum & Colon & Kidney & Muscle \\
\hline Basal & $6925(435)$ & $251(13)$ & $149(0.9)$ & $150(3.9)$ & $268(21)$ & $286(13)$ & $193(8.5)$ & $11385(50)$ & $47(3.2)$ \\
\hline TNF/vehicle & 7929 (18) & $757(26)^{\star}$ & $434(33)^{\star}$ & $280(11)^{\star}$ & $450(8.0)^{\star}$ & $477(28)^{\star}$ & $352(7.3)^{\star}$ & $2259(158)^{\star}$ & $143(3)^{\star}$ \\
\hline $\mathrm{TNF} /$ heparin & $8991(589)$ & $645(8.5)^{\star}$ & $427(24)^{\star}$ & $278(9.6)^{\star}$ & $459(16)^{\star}$ & $438(32)^{\star}$ & $329(8.3)^{\star}$ & $1969(10)^{\star}$ & $119(17)^{\star}$ \\
\hline
\end{tabular}

${ }^{\star} \mathrm{p}<0.05 v$ basal.

Table 3 Endothelial expression of VCAM-1 (ng of $m A b / g$ tissue) on different organs under basal unstimulated conditions ( $n=5)$ or five hours after $T N F-a$ injection, in vehicle or heparin pretreated rats $(n=4)$

\begin{tabular}{|c|c|c|c|c|c|c|c|c|c|}
\hline & Lung & Heart & Pancreas & Stomach & Small bowel & Caecum & Colon & Kidney & Muscle \\
\hline Basal & $195(30)$ & $11.2(0.4)$ & $8.4(1.1)$ & $6.0(1.3)$ & $6.3(0.9)$ & $5.9(0.8)$ & $3.3(0.4)$ & $84.5(10.5)$ & $2.6(0.2)$ \\
\hline TNF/vehicle & $361(36)^{\star}$ & $83.5(1.5)^{\star}$ & $43.5(2.5)^{\star}$ & $19.5(0.5)^{\star}$ & $38.5(1.5)^{\star}$ & $38.5(0.5)^{\star}$ & $28.0(2.0)^{\star}$ & $206(5.5)^{\star}$ & $14.0(2.0)^{\star}$ \\
\hline $\mathrm{TNF} /$ heparin & $307(2.5$ & $78.5(12)^{\star}$ & $36.5(1.5)^{\star}$ & $19.0(1.0)^{\star}$ & $30.0(3.0)^{\star}$ & $33.5(0.5)^{\star}$ & $22.5(2.5)^{\star}$ & $199(23)^{\star}$ & $11.0(1.0)^{\star}$ \\
\hline
\end{tabular}


Table 4 Endothelial expression of P-selectin ( $n g$ of $m A b / g$ tissue) on different organs under basal unstimulated conditions ( $n=4)$ or two hours after $T N F-a$ injection, in vehicle or heparin pretreated rats $(n=4)$

\begin{tabular}{|c|c|c|c|c|c|c|c|c|c|}
\hline & Lung & Heart & Pancreas & Stomach & Small bowel & Caecum & Colon & Kidney & Muscle \\
\hline Basal & $18.2(6)$ & $0.1(0.2)$ & $0.9(0.4)$ & $0.4(0.1)$ & $1.2(0.2)$ & $1.5(0.3)$ & $0.4(0.2)$ & $-1.1(0.1)$ & $0.18(0.1)$ \\
\hline TNF/vehicle & $15.3(8.0)$ & $3.7(1.7)$ & $13.4(3.1)^{\star}$ & $6.2(2.1)^{\star}$ & $12.9(3.1)^{\star}$ & $10.1(2.4)^{\star}$ & $5.9(1.4)^{\star}$ & $2.9(2.2)$ & $6.2(1.8)^{\star}$ \\
\hline $\mathrm{TNF} /$ heparin & $5.8(3.9)$ & $2.3(0.9)$ & $11.8(3.0)^{\star}$ & $4.0(1.2)^{\star}$ & $12.0(2.6)^{\star}$ & $9.5(2.3)^{\star}$ & $5.2(1.6)^{\star}$ & $-3.4(0.6)^{\star}$ & $4.3(0.7)^{\star}$ \\
\hline
\end{tabular}

${ }^{\star} \mathrm{p}<0.05 v$ basal.

Table 5 CD11a and L-selectin expression (arbitrary units of fluorescence intensity) in neutrophils under basal conditions and at two and five hours after $T N F-a$ administration $(n=8-10)$

\begin{tabular}{llll}
\hline & Basal & $2 h T N F-a$ & $5 h T N F-a$ \\
\hline CD11a & $42.5(3.4)$ & $81.6(16.6)$ & $127.3(19.6)^{\star}$ \\
L-selectin & $53.0(7.0)$ & $67.0(22.0)$ & $58.1(2.1)^{\star}+\dagger$ \\
\hline
\end{tabular}

${ }^{\star} \mathrm{p}<0.01 v$ basal; $\dagger+\mathrm{p}<0.01 v 2 \mathrm{~h} \mathrm{TNF}-\alpha$.

in the mesenteric vasculature. Similar results were observed in all organs (tables 2, 3).

Endothelial P-selectin expression

Expression of P-selectin was also significantly increased when assessed two hours following TNF- $\alpha$ administration compared with baseline conditions in most organs studied (pancreas, stomach, small bowel, caecum, colon, and muscle) (table 4) as well as in the mesenteric vascular endothelium (fig 3). Heparin pretreatment did not attenuate $\mathrm{TNF}-\alpha$ induced expression of P-selectin in the mesenteric vasculature (fig 3) or in other organs (table 4).

EXPRESSION OF NEUTROPHIL ADHESION MOLECULES IN RESPONSE TO TNF- $\alpha$ Neutrophil CD11a and CD11b expression in $T N F-a$ stimulated rats: effect of heparin pretreatment

CD11a and CD11b expression on neutrophils from $\mathrm{TNF}-\alpha$ treated rats remained unchanged compared with baseline, after two hours of an inflammatory stimulus, but a significant increase (two to threefold) in expression of both integrins was detected on neutrophils obtained five hours after TNF- $\alpha$ administration (table 5; fig 4). Neither CD11a nor CD11b upregulation was modified by pretreatment of rats with heparin. Preincubation of leucocytes with heparin-BSA significantly diminished the binding of an anti-CD11b antibody to neu-

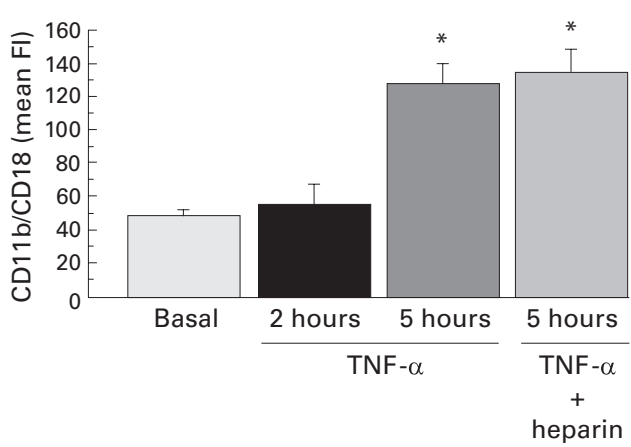

Figure 4 CD11b expression (arbitrary units of fluorescence intensity (FI)) on neutrophils under basal conditions $(n=8)$ and two $(n=4)$ and five hours $(n=8)$ after administration of $5 \mathrm{mg} / \mathrm{kg}$ of TNF-a to rats. Pretreatment with heparin before TNF-a injection did not prevent CD11b upregulation observed five hours after TNF-a injection $(n=4) .{ }^{*} p<0.05 v$ basal. trophils obtained from animals five hours after TNF- $\alpha$ injection but not from those obtained under baseline conditions. In contrast, preincubation of these leucocyte preparations with heparin-BSA did not affect binding of the antiCD11a antibody (fig 5), and preincubation of cells with BSA alone had no effect on binding of any $\mathrm{mAb}$ (data not shown).
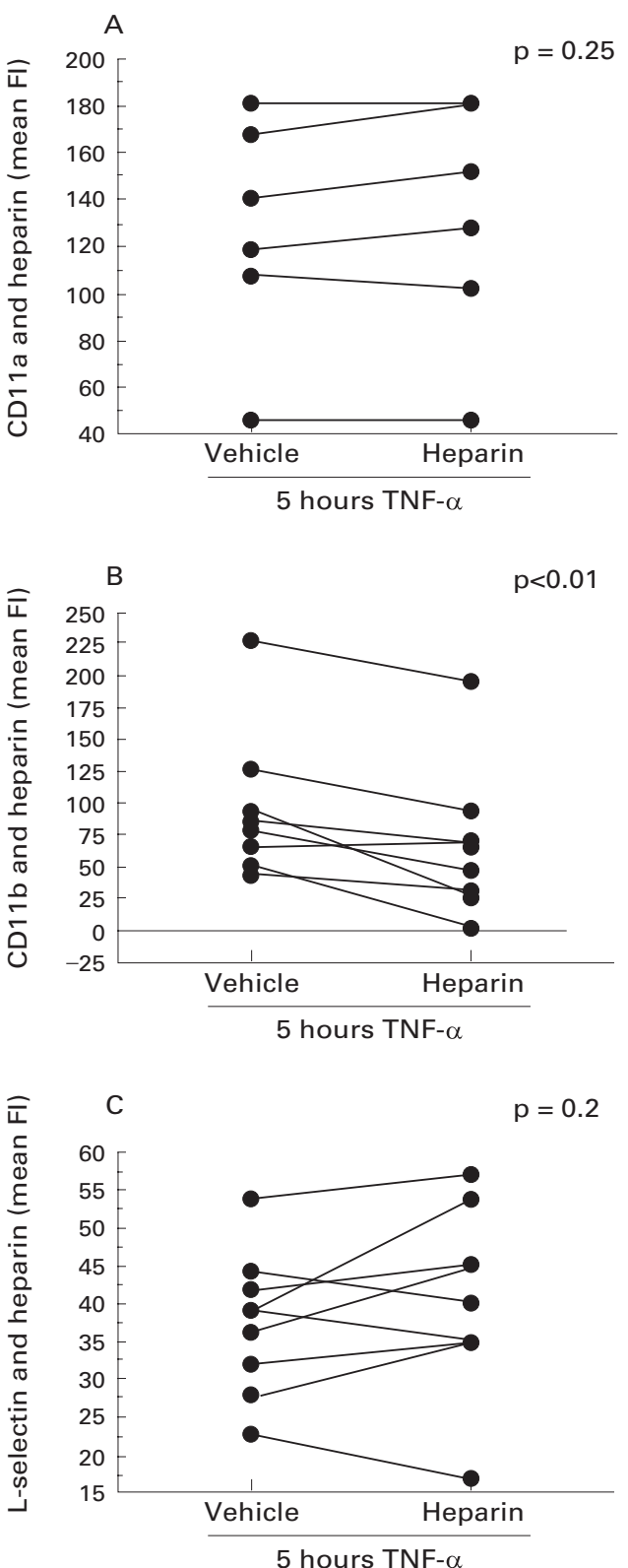

Figure 5 CD11a, CD11b, and L-selectin expression (arbitrary units of fluorescence intensity (FI)) on neutrophils five hours after TNF-a injection. Coincubation of neutrophils with heparin significantly diminished anti-CD11b antibody binding (B) but did not affect anti-CD11a $(A)$ or anti-L-selectin binding $(C)$. Each line represents an individual test animal. 


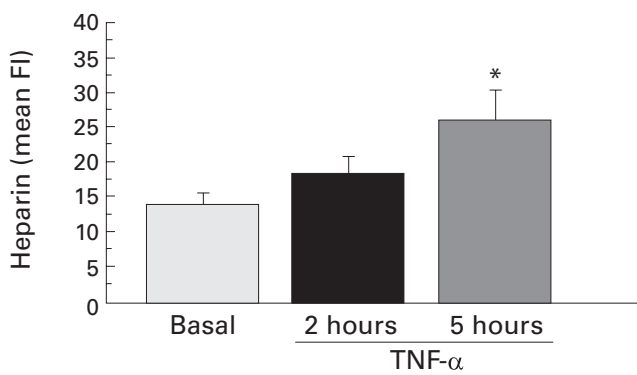

Figure 6 Binding of heparin (arbitrary units of fluorescence intensity (FI)) to neutrophils under basal conditions $(n=6)$ and two $(n=4)$ and five hours $(n=8)$ after TNF-a administration. ${ }^{*} p<0.05$ v basal.

Neutrophil L-selectin expression in TNF-a stimulated rats: effect of heparin pretreatment L-selectin expression on neutrophils from rats stimulated for two hours with $\mathrm{TNF}-\alpha$ was similar to that observed on neutrophils obtained under baseline conditions. However, L-selectin levels were significantly decreased five hours after TNF- $\alpha$ administration (table 5). Preincubation of leucocytes with heparinBSA ex vivo did not significantly affect anti-Lselectin binding to neutrophils obtained under either basal conditions or at two (data not shown) or five hours after TNF- $\alpha$ injection (fig 5).

BINDING OF HEPARIN TO NEUTROPHILS EX VIVO When isolated from test animals under baseline conditions, $73 \%$ of neutrophils bound heparin, as revealed in a streptavidin-PE binding assay described in methods. The percentage of neutrophils that bound heparin and the intensity of this binding significantly increased when assessed five hours, but not two hours, after TNF- $\alpha$ treatment, suggesting that heparin binds a leucocyte surface molecule which is also significantly upregulated after five hours of exposure to TNF- $\alpha$ (fig 6). Preincubation of leucocytes with an anti-CD11b mAb, but not anti-CD11a or anti-L-selectin mAb, significantly reduced the binding of heparin to neutrophils, supporting the concept that heparin binds to CD11b under these experimental conditions (fig 7).

INFLAMMATORY RESPONSE TO FMLP IN MESENTERIC VENULES: EFFECTS OF HEPARIN PRETREATMENT

fMLP is a potent chemotactic agent that activates leucocytes and induces a CD11b dependent adhesion to artificial or biological substrates. $^{37}$ To provide further evidence for molecular interactions between heparin and CD11b, we studied the effect of heparin on leucocyte-endothelial cell interactions elicited by fMLP in vivo. fMLP potently induced leucocyte adhesion within 30 minutes after superfusion of mesenteric venules (basal 3.2 (0.25) cells $/ 100 \mu \mathrm{m}$, fMLP 15.5 (4.4) cells $/ 100$ $\mu \mathrm{m} ; \mathrm{p}<0.01 v$ baseline) but had no significant effect on the extent of leucocyte migration compared with that observed under baseline conditions (data not shown). The hyperadhesive response to fMLP was significantly inhibited by pretreatment with heparin (5.6 (1.4)
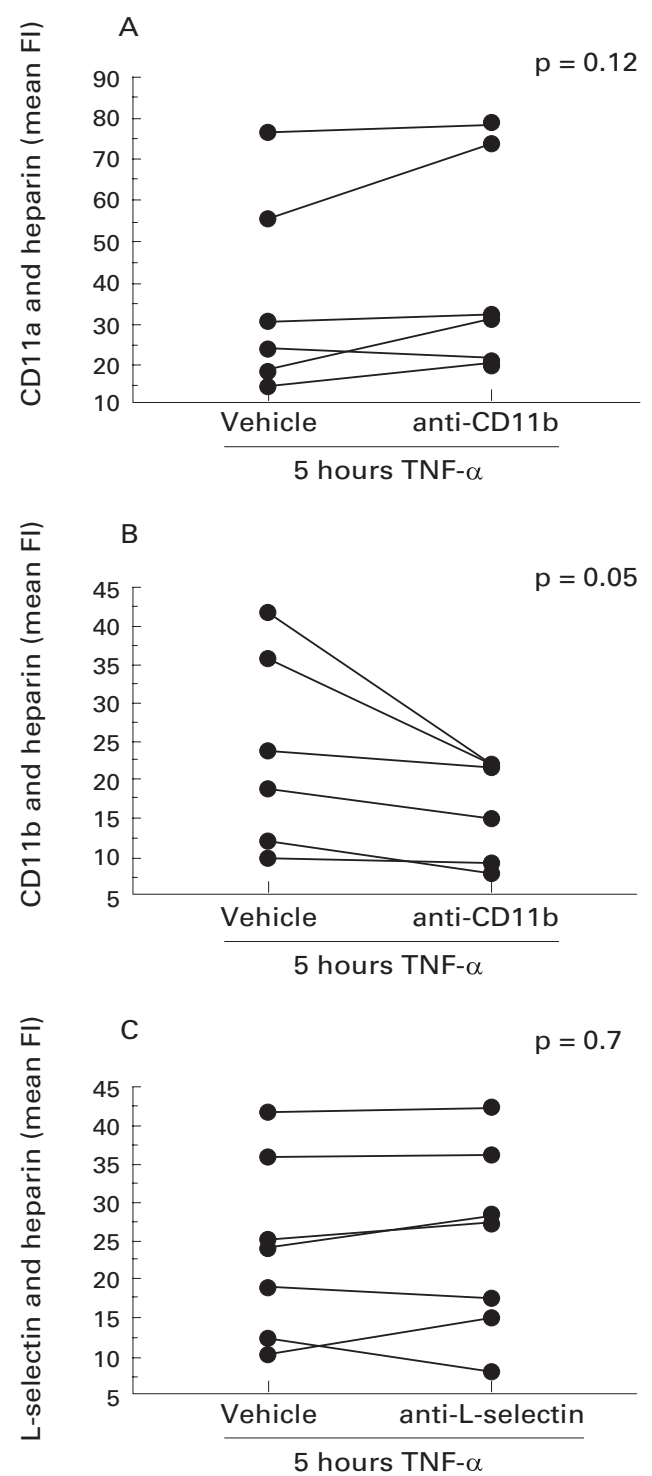

Figure 7 Binding of heparin-biotin (arbitrary units of fluorescence intensity (FI)) to neutrophils obtained five hours following TNF-a stimulation. Coincubation with an anti-CD11b antibody (B) but not an anti-CD11a $(A)$ or anti-L-selectin antibody $(C)$ significantly reduced binding of heparin to neutrophils. Each line represents an individual animal.

cells $/ 100 \mu \mathrm{m} ; \mathrm{p}<0.05 v$ fMLP treatment), supporting the notion that heparin interferes with a CD11b dependent process.

EFFECT OF HEPARIN DOSES ON APTT

Treatment of test animals with either 50 or $500 \mathrm{U} / \mathrm{kg}$ (the dose demonstrating maximal anti-inflammatory effects) of heparin did not significantly prolong aPTT compared with that of untreated control animals (controls, 17.3 (1.45) seconds; $50 \mathrm{U} / \mathrm{kg}, 21.3$ (0.27) seconds; $500 \mathrm{U} / \mathrm{kg}, 20.6$ (0.87) seconds; NS $v$ control). In contrast, treatment with $1500 \mathrm{U} / \mathrm{kg}$ of heparin caused significant anticoagulation with prolongation of aPTT values $\geqslant 1.5$ times those of untreated animals (26.2 (2.2) seconds; $\mathrm{p}<0.05 v$ control).

\section{Discussion}

Our study demonstrates for the first time that systemic administration of heparin markedly 
reduces the inflammatory response elicited by $\mathrm{TNF}-\alpha$ in vivo. Using intravital microscopy, we quantified leucocyte-endothelial cell interactions after challenging test animals with TNF- $\alpha$. Both the flux of rolling leucocytes and the number of adherent and migrated leucocytes, as well as microvascular permeability, were significantly increased by TNF- $\alpha$, and this inflammatory response was significantly attenuated by heparin pretreatment. Of the mechanisms leading to leucocyte recruitment, induction of adhesion molecule expression represents a critical event in the onset of an inflammatory response. Therefore, we carried out studies to test the hypothesis that heparin may interfere with expression or functional activity of selected adhesion molecules involved in TNF- $\alpha$ induced inflammation and thereby reduce leucocyte recruitment and associated inflammatory injury. We found three lines of evidence to suggest that the antiinflammatory action of heparin is related to interaction with leucocyte CD11b in vivo: (1) the time course and magnitude of the increase in CD11b expression after treatment with $\mathrm{TNF}-\alpha$ paralleled that of heparin binding to neutrophils; (2) binding of heparin to TNF- $\alpha$ activated neutrophils was significantly diminished by preincubation of these cells with an anti-CD11b antibody; and (3) heparin preincubation inhibited the binding of an antiCD $11 b$ antibody to TNF- $\alpha$ stimulated neutrophils.

A receptor-ligand interaction between heparin and CD11b was first described by Diamond and colleagues using affinity resins and cells transfected with Mac-1 or neutrophils activated with IL-8 and fMLP. ${ }^{25}$ In the current study, we tested the capacity of heparin to block fMLP induced and CD11b dependent leucocyte adhesion in vivo. Heparin significantly inhibited adhesion of leucocytes to the venular wall in response to this chemotactic factor. Collectively, these observations support the notion that the interaction of heparin with activated CD11b accounts for inhibition of leucocyte adhesion and migration normally observed in TNF- $\alpha$ treated animals. The finding that heparin attenuated leucocyte migration across vascular endothelium five hours, but not two hours, after TNF- $\alpha$ exposure suggests that heparin may interfere with the binding of an adhesion molecule that is upregulated at this time. Although CD11a was also upregulated five hours after TNF- $\alpha$ injection, we found no evidence of heparin binding to CD11a.

As firm adhesion and eventual migration in response to TNF- $\alpha$ also depend on upregulation of endothelial expression of ICAM-1 and VCAM-1, we investigated if expression of these transcriptionally regulated molecules was increased five hours after TNF- $\alpha$ challenge, and if this level of expression was reduced by pretreatment with heparin. Our results demonstrated that expression of ICAM-1 on mesenteric endothelium was doubled and that expression of VCAM-1 increased fourfold, five hours after intraperitoneal injection of TNF- $\alpha$. However, these increases were not significantly modified by pretreatment of rats with unfractionated heparin. We cannot rule out the possibility that heparin binds to and directly or indirectly interferes with the function of these adhesion molecules, as mAbs used in our experiments may bind to epitopes distinct from heparin binding sites on endothelial cells. Further studies in vitro incorporating purified proteins are required to address the possibility that heparin binds to adhesion molecules on endothelial cells.

Previous reports have documented the ability of heparin to inhibit leucocyte rolling in mesenteric venules under basal and stimulated conditions, physiological events known to depend on $\mathrm{P}$ - and L-selectin expression. ${ }^{38}$ In the current study, we also showed that heparin attenuated the increase in leucocyte rolling apparent two hours following systemic administration of $T N F-\alpha$. We observed that P-selectin was significantly upregulated in vivo at the same time interval after TNF- $\alpha$ injection and coincident with observations of maximal leucocyte rolling. Although increased P-selectin expression was not affected by pretreatment of animals with heparin, it is possible that heparin may reduce leucocyte rolling through binding to this selectin molecule and thereby interfere with its function; this requires further study.

Another potential anti-inflammatory target for heparin is L-selectin. Our flow cytometry assays revealed a significant decrease in L-selectin expression on leucocytes obtained from animals five hours after $\mathrm{TNF}-\alpha$ treatment, but not during the first two hours of treatment, when leucocyte rolling was observed to be maximal. Thus these results suggest that the anti-inflammatory action of heparin is not mediated through modulation of L-selectin on activated neutrophils. Systemically administered heparin did not change L-selectin expression levels two hours after TNF- $\alpha$ injection. Moreover, incubation with an anti-Lselectin $\mathrm{mAb}$ did not interfere with heparin binding to neutrophils ex vivo, as assessed by flow cytometry. Although previous reports have demonstrated the ability of heparin to bind L-selectin in in vitro systems, ${ }^{13}$ our studies provide no evidence of heparin binding to L-selectin under in vivo conditions.

Finally, our studies suggest that the antiinflammatory action of heparin is not dependent on its anticoagulant properties as a dose of heparin that showed maximal inhibition of the inflammatory response to $\mathrm{TNF}-\alpha$ did not significantly prolong the aPTT when administered systemically to rats. These findings suggest that it may be possible to use heparin at doses capable of achieving anti-inflammatory activity without increasing the risk of haemorrhagic complications in IBD patients.

The authors thank Dr Pilar Pizcueta (Hepatology Department, Hospital Clínic, Barcelona, Spain) and Dr Roy Lobb, Biogen Inc. (Cambridge, Massachusetts, USA), for kindly providing mAbs LAM 1.116 and $5 \mathrm{~F} 10$, respectively. This work was supported by grants from Comisión Interministerial de Ciencia y Tecnología (SAF97/0040 and SAF00/0057). 
1 Gaffney PR, Doyle CT, Gaffney A, et al. Paradoxical response to heparin in 10 patients with ulcerative colitis. Am f Gastroenterol 1995;90:220-3.

2 Gaffney P, Gaffney A. Heparin therapy in refractory ulcerative colitis - an update. Gastroenterology 1996;110:A913.

3 Evans RC, Rhodes JM. Treatment of corticosteroidresistant ulcerative colitis with heparin. A report of nine cases. Gut 1995;37:A49.

4 Brazier F, Yzet T, Duchmann JC, et al. Effect of heparin treatment on extraintestinal manifestations associated with inflammatory bowel diseases. Gastroenterology 1996;110: A872.

5 Brazier F, Yzet T, Boruchowicz A, et al. Treatment of ulcerative colitis with heparin. Gastroenterology 1996;110: A872.

6 Dupas JL, Brazier F, Yzet T, et al. Treatment of active Crohn's disease with heparin. Gastroenterology 1996;110: A900.

7 Folwaczny C, Spannagl M, Wiebecke W, et al. Heparin in the treatment of highly active inflammatory bowel disease the treatment of highly active inflammatory bowe

8 Dwarakanath AD, Yu LG, Brookes C, et al. 'Sticky' neutrophils, pathergic arthritis, and response to heparin in pyoderma gangrenosum complicating ulcerative colitis Gut 1995;37:585-8.

9 Fries W, Pagiaro E, Canova E, et al. The effect of heparin on trinitrobenzene sulphonic acid-induced colitis in the rat. Aliment Pharmacol Ther 1998;12:229-36.

10 Noguchi M, Hiwatashi N, Liu Z, et al. Secretion imbalance between tumour necrosis factor and its inhibitor in inflammatory bowel disease. Gut 1998;43:203-9.

11 Mazlam MZ, Hodgson HJ. Peripheral blood monocyte cytokine production and acute phase response in inflammatory bowel disease. Gut 1992:33:773-8.

12 D'Haens G, Van Deventer S, Van Hogezand R, et al. Endoscopic and histological healing with infliximab anti-tumor necrosis factor antibodies in Crohn's disease: A European multicenter trial. Gastroenterology 1999;116:1029-34.

13 Nelson RM, Cecconi O, Roberts WG, et al. Heparin oligosaccharides bind L- and P-selectin and inhibit acute oligosaccharides bind L- and P-selectin

14 Lantz M, Thysell H, Nilsson E, et al. On the binding of tumor necrosis factor (TNF) to heparin and the release in vivo of the TNF-binding protein I by heparin. $\mathcal{F}$ Clin Inves 1991;88:2026-3

15 Tyrell DJ, Kilfeather S, Page CP. Therapeutic uses of heparin beyond its traditional role as an anticoagulant Trends Pharmacol Sci 1995;16:198-204

16 Hocking D, Ferro TJ, Johnson A. Dextran sulfate and heparin sulfate inhibit platelet-activating factor-induced pulmonary edema. F Appl Physiol 1992;72:179-85.

17 Darien BJ, Fareed J, Centgraf KS, et al. Low molecular weight heparin prevents the pulmonary hemodynamic and pathomorphologic effects of endotoxin in a porcine acute lung injury model. Shock 1998;9:274-81.

18 Meyer J, Cox CS, Herndon DN, et al. Heparin in experimental hyperdynamic sepsis. Crit Care Med 1993;21: $84-9$

19 Hiebert LM, Liu JM. Heparin protects cultured arterial endothelial cells from damage by toxic oxygen metabolites. endothelial cells from damage
Atherosclerosis 1990;83:47-51.

20 Matzner Y, Marx G, Drexler R, et al. The inhibitory effect of heparin and related glycosaminoglycans on neutrophi chemotaxis. Thromb Haemost 1984;52:134-7.
21 Bazzoni G, Beltran NA, Mascellani G, et al. Effect of heparin, dermatan sulfate, and related oligo-derivatives on human polymorphonuclear leukocyte functions. 7 Lab Clin human polymorphonuci

22 Teixeira MM, Hellewell PG. Suppression by intradermal administration of heparin of eosinophil accumulation but not oedema formation in inflammatory reactions in guinea-pig skin. Br f Pharmacol 1993;110:1496-500.

23 Carr J. The anti-inflammatory action of heparin: heparin as an antagonist to histamine, bradykinin and prostaglandin E1. Thromb Res 1979;16:507-16.

24 Koenig A, Norgard SK, Linhardt R, et al. Differential interactions of heparin and heparan sulfate glycosaminoglycans with the selectins. Implications for the use of unfractionated and low molecular weight heparins as therapeutic ated and low molecular weight heparin

25 Diamond MS, Alon R, Parkos CA, et al. Heparin is an adhesive ligand for the leukocyte integrin Mac-1 (CD11b/ CD18). F Cell Biol 1995;130:1473-82.

26 Benimetskaya L, Loike JD, Khaled Z, et al. Mac-1 (CD11b/ $\mathrm{CD} 18$ ) is an oligodeoxynucleotide-binding protein. Nat Med 1997;3:414-20.

27 Henninger DD, Panes J, Eppihimer M, et al. Cytokineinduced VCAM-1 and ICAM-1 expression in different organs of the mouse. F Immunol 1997;158:1825-32.

28 Walter UM, Ayer LM, Wolitzky BA, et al. Characterization of a novel adhesion function blocking monoclonal antibody of a novel adhesion function blocking monoclonal antibody to rat/mouse P-selectin generated in the

29 Tamatani T, Miyasaka M. Identification of monoclonal antibodies reactive with the rat homolog of ICAM-1, and evidence for a differential involvement of ICAM-1 in the adherence of resting versus activated lymphocytes to high endothelial cells. Int Immunol 1990;2:165-71

30 Sanz MJ, Hartnell A, Chisholm P, et al. Tumor necrosis factor alpha-induced eosinophil accumulation in rat skin is dependent on alpha4 integrin/vascular cell adhesion molecule-1 adhesion pathways. Blood 1997;90:4144-52.

31 Ma L, Raycroft L, Asa D, et al. A sialoglycoprotein from human leukocytes functions as a ligand for P-selectin. $\mathcal{F}$ Biol Chem 1994;269:27739-46.

32 Fraker PJ, Speck JC. Protein and cell membrane iodination with a sparingly soluble chloramine. Biochem Biophys Res Commun 1978;80:849-56.

33 Morise Z, Komatsu S, Fuseler JW, et al. ICAM-1 and P-selectin expression in a model of NSAID-induced gastropathy. Am f Physiol 1998;274:246-52.

4 Panes J, Gerritsen ME, Anderson DC, et al. Apigenin inhibits tumor necrosis factor-induced intercellular adhesion molecule-1 upregulation in vivo. Microcirculation 1996;3: 279-86

35 Sans M, Panés J, Ardite E, et al. VCAM-1 and ICAM-1 mediate leukocyte-endothelial cell adhesion in rat experimental colitis. Gastroenterology 1999;116:874-83.

36 Panes J, Perez-del-Pulgar S, Casadevall M, et al. Impaired mesenteric leukocyte recruitment in experimental portal
hypertension in the rat. Hepatology 1999;30:445-53.

37 Diamond MS, Springer TA. A subpopulation of Mac-1 (CD11b/CD18) molecules mediates neutrophil adhesion CD11b/CD18) molecules mediates neutrophil adhesion

38 Ley K, Bullard DC, Arbones ML, et al. Sequential contribution of L- and P-selectin to leukocyte rolling in vivo. $\mathcal{F}$ Exp Med 1995;181:669-75. 